\title{
Exploring the Feasibility of Cradle to Cradle (Product) Design: Perspectives from New Zealand Scientists
}

\author{
Stephen D. Reay (Corresponding author) \\ Product + Design, School of Art + Design, Auckland University of Technology \\ 34 St Paul St., Auckland, New Zealand \\ Tel: 64-9-921-9999 extn.6719, Fax: 64-9-921-9916 E-mail: stephen.reay@aut.ac.nz
}

Judith P. McCool

Department of Social and Community Health, School of Population Health, FMHS

The University of Auckland, New Zealand

Andrew Withell

Product + Design, School of Art + Design, Auckland University of Technology

34 St Paul St., Auckland, New Zealand

Tel: 64-9-921-9999 extn.6719 Fax: 64-9-921-9916

\begin{abstract}
This research project explores the feasibility of a Cradle to Cradle approach to sustainable product design in New Zealand. A framework for sustainable design was proposed by environmental chemist Michael Braungart and architect William McDonough who suggest that the current paradigm of "cradle to grave" product development is unable to provide a solution to the world's current ecological crisis, and a "cradle to cradle" framework is more appropriate. They suggest that their approach, based on examples from nature, ensures that all human activities have a positive ecological footprint, capable of replenishing and regenerating natural systems, as well as guaranteeing that we are able to develop a world that is culturally and ecologically diverse. A sample of New Zealand scientists were asked to explore the underlining science and feasibility of the Cradle to Cradle framework in an attempt to determine the potential of this approach for the design of sustainable products. Analysis of interview data indicated that sustainability is a complex and multi-faceted concept, especially with regard to the practical application of ecological considerations, and product design. There is considerable environmental and economic potential in the successful application of interdisciplinary collaboration between science and design when addressing the need for products that contribute to sustainable development.
\end{abstract}

Keywords: Cradle to Cradle design, Sustainable design, Science and design, Ecology, Ecosystems

\section{Introduction}

The design community has responded to the growing concern around social and environmental issues by developing concepts and frameworks such as eco-design and sustainable design, and the numerous related iterations (Sherwin 2004). These concepts are centred on acknowledging ecological limits and demonstrating responsibility, and increased contribution to society and the environment (Sherwin 2004). Approaches generally fall in between two main areas, eco-design or sustainable design (Tischner \& Charter 2001, Sherwin 2004). Eco-design approaches generally aim to incorporate environmental issues into product design and development, with an overall aim of minimising environmental impacts with motivation in the form of economic gains that might result in the corresponding "efficiency" (Tischner \& Charter 2001). These strategies reflect a product development process that considers environmental concerns at each design and manufacturing stage. The goal is to make the smallest environmental impact throughout the product's life (Glavič \& Lukman 2007). Often attempts are made to use materials with low environmental impact in its production, but environmental impacts after the product has been sold are not taken into account (Ljungberg 2007). Sustainable (product) design goes well beyond the principles of eco-design, by incorporating greater innovation, ethics and socio-economic and ecological dimensions by aiming for 'triple bottom line' solutions (Tischner \& Charter 2001, Sherwin 2004). In essence, sustainable design has been orientated toward balancing economic, environmental and social aspects, while minimising adverse sustainable impacts and maximising sustainable value, throughout the life of a product (Tischner \& Charter 2001). 
Sustainable product design is a relatively new discipline in that it positions sustainability (in itself complex and multifaceted) at the heart of every product designed (Fiksel 2001). The concept of sustainability is complex, dynamic, and often nuanced by the context in which is placed (i.e. sustainable forestry, sustainable development, etc.) (Walker 1998, Walker \& Dorsa 2001). In an era that has been charged with the task of addressing issues around climate change and environmental degradation, no other period has imposed the same critical attention to the environmental and social costs of product production and use. This is a new era where environmentalism takes place alongside (but not yet contesting) the discourse of economics. Now more than ever, the role of products and services is central to the sustainability debate. There are significant benefits for those who are able to identify opportunities to develop sustainable products and services (Tischner \& Charter 2001). More specifically, these opportunities will be realised by designers who develop radical innovative solutions by involving sustainability at the early stages of the design process (Sherwin 2004).

\subsection{Cradle to Cradle}

McDonough and Braungart (2002) and Braungart et al. (2007) describe the "Cradle to Cradle" approach as "the next industrial revolution" and suggest that industry needs a new paradigm that effectively and seamlessly addresses issues associated with over-consumption and waste. Central to Cradle to Cradle is the critique of the use of "eco-efficiency" as a driver for developing environmentally benign products and systems. They argue the ultimate goal of eco-efficiency, zero emission, which aims for maximum economic output with zero environmental impacts, is the ultimate endpoint of such an approach and represents a breakdown of the economic and ecological relationship. The authors solution to sustainable development- eco-effectiveness, aims to generate cyclical Cradle to Cradle metabolisms to maintain the status of resources (Braungart et al. 2007). The eco-effective approach starts with a vision that industry is 100 percent good, the concept of waste does not exist (as all outputs from one process become inputs for another), supports and regenerates ecological systems and enables long-term prosperity and is the basis for "triple top line" objectives (Braungart et al. 2007). The Cradle to Cradle framework attempts to turns materials into nutrients by enabling their perpetual flow within either biological or technical metabolisms. In this scenario, biodegradable materials (biological nutrients) are absorbed back into, and have a positive impact on the environment. Synthetic or mineral materials (technical nutrients) remain safely in a closed loop system of manufacture, recovery and reuse to maintain their material value through many cycles, and are owned by manufacturers, but are used by consumers as products of service (Braungart et al. 2007). In eco-effective industrial systems waste becomes biological nutrients for ecological systems, and are therefore ecologically irrelevant to be included into a saleable product (Braungart et al. 2007). The authors suggest that even if enormous amount of waste were generated in production, the system as a whole would become eco-effective, as waste is a productive resource for natural systems.

This study aims to evaluate the application of the Cradle to Cradle design framework from an ecological perspective, in an attempt to determine the feasibility of this approach, for the design of products. A deeper exploration of the Cradle to Cradle design framework is a relevant reference point to reflect where design thinking might currently be, and is a sound basis for initiating a sustainability discussion.

\section{Methods}

A series of key informant interviews was undertaken with New Zealand scientists to explore expert opinion on the feasibility and issues associated with the Cradle to Cradle framework and sustainable design approaches in general. The purpose of conducting key informant interviews was to generate a broad understanding of the key issues, barriers, and opportunities from those who have specific scientific expertise. The Cradle to Cradle framework relies primarily on a fundamental understanding of materials, science, systems and processes. A semi-structured interview format was utilised to guide the interview, to allow differing ideas to surface and for reflective discussion. A thematic analysis of the data was conducted and an explanatory theory based on the emerging themes was subsequently developed. Key informant interviews are an important qualitative research method in terms of providing insight into issues that cannot often be identified through other research methods (e.g. focus group interviews or questionnaires).

\subsection{Participants}

Key informant participants were chosen using a non-probability purposive sampling technique, and selected based on their unique experience in a particular scientific field. The scientists selected were chosen from a range of scientific disciplines related to the primary industries in New Zealand. This group were chosen because they have a broad understanding of the biological processes that underpin sustainability, or the development of materials and processes that may be required for the development of sustainable systems. Each scientist selected was employed in a senior science position in either a Crown Research Institute or New Zealand University. 
Contact details were obtained from information in the public domain.

Potential participants were contacted by an email informing them about the study aims and rationale and inviting their participation. If no response was received following the email invitation to participate, this was taken to mean the individual declined to take part in the study, and no further contact was initiated.

Participants that took part in the study were from the following areas of expertise: biology, material science/engineering, biotechnology, science strategy, chemical and process science/engineering, pharmacology and active agent science, microbiology, and textiles science.

\subsection{Procedure}

Prior to the commencing of the interview process, approval to carry out the study was sought and obtained from the Auckland University of Technology Ethics Committee (AUTEC Reference Number 09/54).

Participants were invited to take part in a key informant interview to discuss a range of topics centred on sustainability and Cradle to Cradle design. Participants were provided with an abbreviated version of the Cradle to Cradle framework (Braungart et al. 2007) and it was from this basis that the interviews were conducted. The interviews were based around a series of open-ended questions (described below) and enabled the participants to explore the questions in-depth.

Key informant interview themes/questions

1) What is the role of sustainability in the context of your science field?

2) What materials are important/critical to achieve sustainable products?

3) What do you understand about the concept of Cradle to Cradle as a proposition for sustainability with respect to science/design?

a) What were your first impressions with respect to the principles that underpin the concept?

b) What is the potential of this concept for New Zealand science/technology?

c) What is the role of science to help facilitate a Cradle to Cradle framework?

d) Can New Zealand embrace this concept, and what do you see as potential barriers/opportunities?

4) How do you view the role of scientists/science in adopting a concept like Cradle to Cradle?

New questions were included to reflect emerging issues as interviews progressed. Interviews were audio recorded to enable transcripts to be used for analysis. Detailed field notes were also taken during the interviews, where possible, to complement the transcripts. Interviews were conducted by SR, took no longer than one hour, and were conducted in the participants' workplace at a time that was convenient for them.

The interviews were analysed using a qualitative thematic analysis method whereby the textual data was read and coded to identify common and divergent viewpoints (Berg 1998). The key perspectives or themes were developed in consultation with co-authors and when agreement was reached, they were then developed into an explanatory model. All possible attempts were made to obscure the contribution of participants to protect their identities, including their place of employment, age and gender.

\section{Results}

Results from the textual analysis of the interview data are presented according to the key (dominant) themes. Descriptive statistics are presented to show the number of participants who described a similar viewpoint or theme (Table 1). Direct quotations are presented to illustrate a pervasive or idiosyncratic perspective. The themes will be presented in respective order: informants' general impressions of the Cradle to Cradle design framework; a critique of the Cradle to Cradle design framework; barriers preventing sustainable design frameworks from being broadly implemented and opportunities for sustainable design in New Zealand. Finally, this section concludes with the emergent themes around the future of sustainable design in the context of New Zealand, and the potential role of science and technology.

\subsection{General impressions of the Cradle to Cradle design framework}

Most participants had not heard of the Braungart et al. (2007) Cradle to Cradle design framework prior to participating in this study. All participants expressed a diverse range of perspectives on the general concepts and rationale behind the Cradle to Cradle framework. In general, participants agreed that the general principles that underpin Cradle to Cradle are important factors when attempting to address sustainability.

"It's an interesting concept... You know so it sounds like the sensible way to go to me..." (Materials 


\section{Engineer/Scientist)}

Participants supported Braungart et al. (2007)'s interpretation of the tension between economic growth and environmental objectives. Specifically, the concept of "eco-efficiency" as a strategy to resolve issues around resource use and provide a sustainable future was viewed as "accurate". Although participants were generally favourable toward the rationale for Cradle to Cradle the majority considered it to be idealistic: a good idea in principle, but not in practice. Overall, it was it was not widely accepted as a mechanism that would reflect the realities of complex social and environmental ecosystems.

"I felt the general scope was idealistic. Not to say that it's bad. Just that I wouldn't want to totally adhere to it" (Biotechnologist)

"I think the model's been well thought through but I worry that they tried to apply it in ways that perhaps it doesn 't comfortably fit" (Chemical and Process Engineer/Scientist)

There was not a clear consensus as to whether Cradle to Cradle was an appropriate approach to use as a principal for product design. One participant felt that it had merit on a product-to-product basis, but that moving to society level sustainability was an entirely different proposition. Another suggested that it was an appropriate approach, but questioned whether "it was the only approach". Another believed it did not add anything new. Throughout the interviews, the participants agreed that greater effort is required to develop modes of living, and products to assist healthy productive lives that also support future generations.

\subsection{Can we have a positive impact?}

The majority of participants viewed the goals of reducing human impacts to zero as a more realistic goal than attempting to produce positive impacts on the environment.

"Your impact on the environment, you can't absolutely reduce it to zero... everything we do [has] an environmental impact ... and I think what, the aim of this paper I mean, might be zero waste but I think, but there's always going to be this inefficiency somewhere in the system that requires some leakage, you can't have... I don't think you can have a perfect system" (Biologist)

Participants were generally in consensus around the issue that to have a positive impact we must know what that positive might be. They argued that this may not always be the case, and some added that even if it was, we might not have the capability to measure such impacts.

"Because suggesting you actually know what's positive for the environment... we don't seem to have a handle on the complexities of how things interrelate to know precisely what the outcomes will be, so I think it sounds a very strange thing to think that we can do things for the positive to be honest... So I think I'm still a fan of doing as little damage as possible" (Materials Engineer/Scientist)

“... some of these things you can probably never measure... Do we have to measure anything just to get a sense that we would be better off doing it one way rather than another way... I don't think we do" (Microbiologist)

Four participants discussed the complexity around deciding what is natural (and therefore what is "good" for the environment), and observed looking to nature for inspiration may not always be appropriate. Reasons included a description of nature as being very complex, and a failure to recognise this when "fixing" one thing may cause a problem elsewhere. The overwhelming consensus was that regardless of whether a positive impact on the environment was possible or not, it was important to minimise impacts as much as possible in the short to medium term.

\subsection{Is waste always good?}

While the ideas of biological and technical nutrient cycles were generally viewed as being interesting, some participants argued that these approaches might not always be possible, or practical. As anticipated, some participants agreed in principle with the concept of biological nutrient cycles. However the majority cautioned the risks of extrapolating a theoretical principle to real world situations. In particular, participants question the potentially enormous quantities of biological nutrients that might be produced, and questioned how this 'natural' waste would be managed, especially as high levels of nutrient inputs can have detrimental impacts on ecological systems. One participant described that the transition from a largely inorganic system to an organic system would be required to fulfil Cradle to Cradle requirements. While this in itself was viewed positively, most products currently produced are not made from organic-based materials. The result of this could be large quantities of organic "waste" material. One participant observed this was "fine when things are in village amounts, but with city amounts you get problems".

Three participants suggested that knowing where to put the biological nutrients and knowing what influence they 
may have on a system was an issue.

“... put it in an environment where its waste can be utilised, not just thrown in an inappropriate place... is all waste good?, it depends upon how it is going to be utilised" (Biotechnologist)

The application of something as simple as a fertiliser was described as having a significant impact on an ecosystem, especially with regard to soil micro-organisms, reflecting the complexity surrounding inputs into natural systems.

“...Well, you put that fertilizer on for a reason and you want it to actually renew a system... the microbes will respond in a certain way. Some of them will love it, some of them will hate it and you will change the makeup of the soil... It's not necessarily good or bad, but its changed... But what's happened in the soil, is that sustainable?" (Science Strategist)

Energy and time were considered important when addressing the principal of "biological nutrients". One participant suggested that long term thinking ("a time bound") was required to transition from product to biological nutrient, and even longer for the biological nutrient to become the "next organic". Furthermore "there's an energy input is really part of the equation", and "you've got to assume for some of this that energy is low cost."

One participant suggested that the controlled composting of biological waste material was important, as "uncontrolled composting is not efficient, and doesn't always produce a usable bio-product".

While many of the participants found the idea of a technical nutrient cycle appealing, six of the eight participants thought the degradation of materials in this cycle wasn't fully addressed in the Cradle to Cradle framework. Comments ranged from not illustrating that the material integrity of synthetic materials degrades with use, and repeated reuse, to suggestions that all materials wear out during use.

“...so I don't think it's appropriate to just think in an idealistic fashion that materials can be recycled ad infinitum." (Biotechnologist)

“... it's not perhaps a loop, more of a very slow downward spiral" (Textiles Scientist)

Furthermore metals (as potential technical nutrients) were described as oxidising and wearing out. While it was suggested that processes such as oxidisation might be reversed, this takes considerable energy inputs.

3.4 What do we need to consider when using a new design framework?

One of the common themes that emerged during the analysis was the complexity involved with issues around sustainability.

“...they're not simple issues. It's a complex system. And that's what you're talking about here. Sustainability is a complex system..." (Science Strategist)

Access to clean renewable energy sources was described as being an important aspect of the future of sustainability. Energy, as we currently use it, was described by one of the participants as being the only part of a closed system that disappears due to entropy. They suggested that unlike nature, which has endless energy from the sun, we need energy to create energy.

The majority of participants described the development of better eco-effective or eco friendly materials as being influenced by a variety of factors.

“... what's the rate limiting step, and it's typically creative people and funding and the identifying need. Creative people on their own without an identified need, aren't going to create what's useful. Needs can be stated, but you need people to make it." (Biotechnologist)

It was suggested by one participant that the manufacture of biological-based materials depended on very large quantities of plant materials. Research into base materials and technological challenges associated with using new materials (during manufacture) were examples given by another participant of some of the research challenges. For some base materials, these were not considered to be significant hurdles, but for others it was described as very difficult. The lack of performance by some organic-based materials in comparison with their synthetic counterparts was considered a hurdle in terms of the wider acceptance of organic materials.

3.5 How might science play a role in the design of sustainable products and services?

Participants were generally in agreement with regard to the role that science might play around issues of sustainability. Some participants favoured looking to natural systems for ways of living more sustainably, or for developing and utilising sustainable materials. One participant suggested that sustainability “... will come from 
mimicking nature or fitting into nature's cycles." Another participant suggested we look more to organic materials, and continue research into new ways in which they might be used. It was also suggested we need to look at "old" (organic) materials and to develop new manufacturing processes so we can use them more effectively and efficiently.

Other participants described the role of scientists as helping to negotiate the complexity of systems. Understanding what aspects of systems and processes we need to measure, and how to measure them, were described as being fundamental, for now and into the future. One participant described science measurement as being short term, or at a single point in time, and suggested that measuring positive impacts would therefore be similarly constrained.

A key role of science will be helping to develop solutions, as well as identifying the associated risks. Science was described as a vital process for learning and understanding sustainability problems and solutions ("doing the thinking"). Science was described as "fast moving" and that lack of knowledge should not be barrier, as it historically it might have been. This was also described as being true for issues centred on sustainability.

Five participants described the role of biotechnology, including techniques such as genetic modification, as being essential to maintaining the current human population. One participant suggested that those countries that are philosophically opposed to technologies such as GE will have difficulty addressing issues of sustainability, especially if their populations are growing. Another participant suggested that scientists needed to better describe the benefits of these technologies, and how they will have to be used wisely.

One participant described science as the first step in the process of developing new materials and technologies. New technologies will not be developed in the absence of good science. Beyond that, industry needs to "buy in" to fully realise the opportunities that new technologies offer. This participant described the "dream" as the first part of the process. Science is required to make this happen, so business and consumers may then follow.

\section{Discussion}

In general, the majority of participants were involved in research where issues of sustainability, if not central to it, represented a considerable aspect of their research, or they had an interest in general issues surrounding sustainable futures. Overall participants responded positively to the intent of the Cradle to Cradle framework.

A dominant theme that emerged from the interviews was the complexity associated with understanding the interactions of humans, societies and their environments. To address issues of sustainability with rigour requires an ability to explore and work within complex systems and demands (Bradbury 2002, van Roon \& Knight 2004). The domain of a scientist is to understand interactions between multiple factors (see Bradbury 2002). This requires the capacity to ask questions framed in an appropriate context and the aptitude to interpret and discuss complex results. The key informant interviews illustrate that consideration of human impacts on the environment is critical, and was the most discussed factor when referring to sustainability. While issues of social sustainability and economic sustainability were mentioned they were not regarded with the same level of consideration. From the participants' perspective, the environment was considered the foundation of sustainability. Therefore the protection of biodiversity and the natural systems in which it persists is fundamental to fulfil the principles of sustainable development. While "Our Common Future" describes this as "meeting the needs of the present generation without compromising the ability of future generations to meet their own needs" (WCED1987, p49), van Roon and Knight (2004) describe this definition as the balanced approach whereby ecological needs are weighed against economic and social. They suggest that while this approach is commonly accepted internationally, it represents a framework for weak sustainability. The results from this study support the use of a framework for strong, or ecological sustainability, where decision-making is made within an ecological context (Ekins et al. 2003, van Roon \& Knight 2004). This approach recognises that humans are part of ecological systems, and viewing human activities as being separate from nature will ultimately be unsuccessful. Furthermore, van Roon and Knight (2004) argue that the functional capability of ecosystems need to be central to decision making processes.

A few barriers to implementing some principles of the Cradle to Cradle framework were raised by the participants. These were around the concepts of technical and biological nutrients, the interpretation of nature (or what is natural), and energy use and generation. Some participants questioned whether technical nutrients were suitable for "closed loop" systems. They suggested that the material integrity of synthetics and metals is not always easily maintained. Participants also acknowledged the role of consumerism in helping to create or encourage unsustainable practices, as well as the failure of consumers to pay the "true environmental cost" of this behaviour. Neither of these are fully acknowledged and addressed by Braungart et al. (2007). 
The participants in this study expressed a need for caution when approaching the concept of biological nutrients as a simple solution to sustainability problems. The inherent complexities of ecological systems are confounded further by difficulties around measurement. This situation is further complicated when interactive (i.e. history, age, productivity, habitat heterogeneity and complexity etc.) and intimate (i.e. succession, inter-specific interactions, disturbance, dispersal etc.) factors are added (Jeffries 2006).

Reijnders (2008) criticizes the concept of biological nutrients as "healthy wastes". Firstly, not all plant-derived carbon compounds are degraded in the environment. Many substances that occur naturally are hazardous to other organisms and may be extremely toxic to humans. Furthermore significant ecological devastation can occur when large discharges of biological nutrients enter natural systems (Reijnders 2008). Effects of nutrients on biological systems may be subtler than the described ecological disasters (e.g. algal blooms). The responses of individual species to nutrients are unique. Therefore impacts of nutrient modification on individual species and communities are difficult to predict (Theodose \& Bowman 1997, Weiss, 1999, Klanderud \& Totland 2005). While the influence of soil fertility on plant diversity, production and community structure has been demonstrated for many plant communities, in nutrient deficient systems inputs may more immediately enhance primary production but alter species composition over longer time periods (Theodose \& Bowman 1997). In infertile systems where nutrients have been enhanced by human activities, previously dominant species have been displaced by more competitive species adapted to higher levels of fertility resulting in a decline in conservation, or biodiversity values (Rusek 1993, Norton et al. 2006). In such systems, the application of biological nutrients is unlikely to result in ecologically desirable outcomes. However, in the absence of specific ecological knowledge applying biological nutrients may appear to be a worthy and beneficial practise. Patterns of species diversity changes with changes in fertility have been observed for invertebrates, herpetofauna, birds and soil organisms (e.g. soil ectomycorrhizal fungi) (Provencher et al. 2003, Alberton \& Kuyper 2009). The participants critique of biological nutrients in this study supports Reijnders (2008) conclusion that biological nutrients are not "ecological irrelevant", and therefore all emissions of biological nutrients should not be considered to be intrinsically 'good' or 'healthy'.

In the commercial sector, design "disasters" are frequent- based upon superficial design responses to sustainability issues. These are probably due to a failure of designers to understand the complexity of ecological systems (e.g. a compostable mobile phone case that releases a seed on disintegration, Bhamra and Lofthouse 2007). Braungart et al. (2007) describe a potential Cradle to Cradle design solution where an ice cream wrapper may be designed to contain seeds to be thrown away while supporting plant life. While the growing of plants appears to be a worthwhile ideal, in New Zealand many "garden plants" have escaped to become invasive weeds resulting in considerable ecological destruction (DOC 2002). The potential negative impact of this eco-approach is likely to be further exaggerated in a global economy where products are shipped and consumed worldwide. The spread of alien invasive species has had considerable impacts on indigenous species worldwide and is a continued threat to global biodiversity (Bright 1998, Mooney \& Hobbs 2000, Myers 2002, Younge 2002).

The concept of a biological nutrient, as identified by Braungart et al. (2007), represents an exciting opportunity for designers who can play an important role in sustainable development. In doing this, they must engage with the appropriate scientific expertise to make the best of new opportunities that may arise from potential paradigm shifts (i.e. Cradle to Cradle framework). This study demonstrates the inherent need for designers to be aware of the ecological consequences of their design actions, and illustrates the need for interdisciplinary collaboration when tackling problems such as sustainable development (Bruce et al. 2004). While designers have embraced looking to nature for a variety of design frameworks, (e.g. Biomimcry (Benyus 2002), Cylic-Solar-Safe (Datschefski 1999) etc.), using these frameworks in isolation of additional specialised disciplinary expertise is likely to be alarmingly inadequate when attempting to quantify both long and short term consequences of design actions on the environment. Future interdisciplinary collaboration has considerable appeal in a scenario where designers may help to identify human needs and scientists help develop solutions that are more appropriate to the greater environment. Inherent in this is that designers must understand the importance of ecological, social and economic systems as they relate to sustainable development. Consequently, designers may more effectively operate as a conduit between science and industry, and effectively and elegantly communicate sustainable solutions to people and the communities in which they live.

Sustainable development relies on clear and accessible dialogue between science and design (as well as a suite other disciplines). Design decisions must be of real benefit to society and the environment as well as being economically relevant, rather than well-intentioned "eco-responses", with inappropriate or inadequate resource investment. This requires designers to ask how products might be designed to address sustainable development in a meaningful way, rather than simply producing consumer objects that are loosely built around preconceived 
ideals that reference sustainability, but don't consider the underlying ecological principles required to meet the principles of sustainable development. Consequently, a challenge to product design is to engage across disciplines to help realise the intention of frameworks such as Braungart et al. (2007)'s Cradle to Cradle. This represents an enormous opportunity to make a substantial contribution to the future wellbeing of societies and the environment in which they exist.

\section{Acknowledgements}

We would like to thank the participants' for contributing their time and expertise to this study.

\section{References}

Alberton, O. \& Kuyper, T.W. (2009). Ectomycorrhizal fungi associated with Pinus sylvestris seedlings respond differently to increased carbon and nitrogen availability: implications for ecosystem responses to global change. Global Change Biology, 15, 166-175.

Benyus, J. A. (2002). Biomimicry: Innovation inspired by nature. New York: Harper Perennial.

Berg, B. (1998). Qualitative Methods for the Social Sciences. USA: Allyn \& Bacon.

Bhamra, T. \& Lofthouse, V. (2007). Design for Sustainability: A practical approach. Hampshire, England: Goweer Publishing Limited.

Bradbury, R. (2002). Futures, predictions and other foolishness. In M.A. Jansen (ed.) Complexity and ecosystem management: the theory and practise of multi-agent systems (pp. 48-62 ). International Society for Ecological Economics. Meeting (2000: Canberra, A.C.T.). England, UK: Edward Elgar Publishing Ltd.

Braungart, M., McDonough, W. \& Bollinger, A. (2007). Cradle-to-cradle design: creating healthy emission- a strategy for eco-effective product and system design. Journal of Cleaner Production, 15, 1337-1348.

Bright, C. (1998). Life out of bounds; bioinvasion in a borderless world. New York: W.W. Norton \& Company Ltd.

Bruce, A., Lyall, C., Tait, J. \& Williams, R. (2004). Interdisciplinary integration in Europe: the case of the Fifth Framework programme. Futures, 36, 457-470.

Datschefski, E. (1999). Cyclic, solar, safe - BioDesign's solution requirements for sustainability. Journal of Sustainable Product Design, 8, 42-51.

DOC (Department of Conservation) (2002). Space Invaders; A summary of the Department of Conservation's strategic plan for managing invasive weeds. Wellington, New Zealand: The Science Publication Unit, Department of Conservation.

Ekins, P., Simon, S., Deutsch, L., Folke, C. \& De Groot, R. (2003). A framework for the practical application of the concepts of critical natural capital and strong sustainability. Ecological Economics, 44, 165-185.

Fiskel, J. (2001). Measuring sustainability in ecodesign. Pp 165-187 in Charter, M and Tischner, U. (eds.) Sustainable solutions: developing products and services for the future. Sheffield, UK: Greenleaf Publishing Limited.

Glavič, P. \& Lukman, R. (2007). Review of sustainability terms and their definitions. Journal of Cleaner Production, 15, 1875-1885.

Jeffries, M. J. (2006). Biodiversity and conservation. UK: Routledge.

Klanderud, K. \& Totland, O. (2005). Simulated climate change altered dominance hierarchies and diversity of an alpine biodiversity hotspot. Ecology, 86, 2047-2054

Ljunberg, L. Y. (2007). Materials selection and design for sustainable products. Materials and Design, 28, 466-479.

McDonough, W. \& Braungart, M. (2002). Cradle to cradle: remaking the way we make things. New York: North Point Press.

Mooney, H. \& Hobbs, R. J. (2000). Invasive species in a changing world. Washington, DC. USA: Island Press.

Myers, N. (2002). Biodiversity and biodepletion: the need for a paradigm shift. In O'Riordan and Stoll-Kleenmann (eds.) Biodividersity, sustainability and human communities: protecting beyond the protected (pp 46-60). Cambridge, England: Cambridge University Press.

Norton, D. A., Espie, P. R., Murray, W. \& Murray, J. (2006). Influence of pastoral management on plant biodiversity in a depleted short tussock grassland, Mackenzie Basin. New Zealand Journal of Ecology, 30, 335-344.

Provencher, L., Litt, A. R. \& Gordon, D. R. (2003). Predictors of species richness in Northwest Florida longleaf pine sandhills. Conservation Biology, 17, 1660-1671

Reijnders, L. (2008). Are emissions or wastes consisting of biological nutrients good or healthy. Journal of Cleaner Production, 16, 1138-1141. 
Rusek, J. (1993). Air-pollution-mediated changes in alpine ecosystems and ecotones. Ecological Applications, 3, 409-413.

Sherwin, C. (2004). Design and sustainability: A discussion paper based on personal experience and observations. Journal of Sustainable Product Design, 4, 421-431.

Theodose, T. A. \& Bownam, W. D. (1997). Nutrient availability, plant abundance, and species diversity in two alpine tundra communities. Ecology, 78, 1861-1872.

Tischner, U. \& Charter, M. (2001). Sustainable product design. In Charter, M and Tischner, U. (eds.) Sustainable solutions: developing products and services for the future (pp 118-138). Sheffield, UK: Greenleaf Publishing Limited.

van Roon, M. \& Knight, S. (2004). Ecological context of development: New Zealand perspectives. Melbourne, Australia: Oxford University Press.

Walker, S. (1998). Experiment in sustainable product design. The Journal of Sustainable Product Design, 7 , 41-50.

Walker, S. \& Dorsa, E. (2001). Making design work sustainably: product design and social equity. The Journal of Sustainable Product Design, 1, 41-48.

WCED. (Ed.). (1987). Our common future: World Commission on Environment and Development. Oxford: Oxford University Press.

Weiss, S. B. (1999). Cars, cows, and checkerspot butterfliers: Nitrogen deposition and management of nutrient-poor grasslands for a threatened species. Conservation Biology, 13, 1476-1486.

Younge, A. (2002). An ecoregional approach to biodiversity conservation in the Cape Floral Kingdom, South Africa. In T. O'Riordan and S. Stoll-Kleenmann (eds.) Biodividersity, sustainability and human communities: protecting beyond the protected (pp 168-188) Cambridge, England: Cambridge University Press.

Table 1. The number of participants who described or expressed...

having previously heard of Braungart et al.'s Cradle to cradle concept $2(25 \%)$

perceiving aspects of $C 2 C$ as positive $\quad 5(62.5 \%)$

$\begin{array}{ll}\text { perceiving aspects of } \mathrm{C} 2 \mathrm{C} \text { as negative } & 6(75 \%)\end{array}$

$\begin{array}{ll}C 2 C \text { as an appropriate approach } & 1(12.5 \%)\end{array}$

supporting the idea that people can have positive impact on the environment $\quad 1(12.5 \%)$

that looking to nature is complex and not always appropriate $\quad 4(50 \%)$

knowing what or how to measure is complex and we may not always know $\quad 5(62.5 \%)$

$\begin{array}{ll}\text { nature is not always perfect } & 2(25 \%)\end{array}$

caution regarding biological nutrients as a solution for sustainability $\quad 6(62.5 \%)$

the description of technical nutrients failed to fully address material degradation $\quad 6(62.5 \%)$

$\begin{array}{ll}\text { sustainability as a complex issue } & 6(62.5 \%)\end{array}$

people as not paying a true environmental cost $\quad 3(37.5 \%)$

$\begin{array}{ll}\text { consumer behaviour as a barrier to sustainability } & 4(50 \%)\end{array}$

energy as a barrier to sustainability $\quad 4(50 \%)$

politics as a barrier to sustainability $\quad 5(62.5 \%)$

economic cost as a barrier to sustainability $\quad 7(87.5 \%)$

$\begin{array}{ll}\text { human nature as crisis driven } & 2(25 \%)\end{array}$

science is required for sustainability $\quad 7(87.5 \%)$

biotechnology is essential to maintain human population $\quad 5(62.5 \%)$ 